\title{
Oxygen cost of breathing and weaning process in newborn infants
}

\author{
J.C. Rozé*, J.M. Liet*, V. Gournay*, T. Debillon*, C. Gaultier**
}

Oxygen cost of breathing and weaning process in newborn infants. J.C. Rozé, J.M. Liet, V. Gournay, T. Debillon, C. Gaultier. @ CERS Journals Ltd 1997.

ABSTRACT: Newborn infants may have a high oxygen cost of breathing (OCB) at the time of being weaned from mechanical ventilation. We hypothesized that this increase in oxygen consumption $\left(V^{\prime} \mathrm{O}_{2}\right)$ could be reduced by using certain weaning ventilatory modes.

We designed a study to assess $V^{\prime} \mathrm{O}_{2}$ during three weaning ventilatory modes: patient triggered ventilation, synchronous intermittent mandatory ventilation (SIMV) and continuous positive airway pressure in $\mathbf{1 6}$ newborn infants before being weaned from mechanical ventilation

In seven infants whose $O C B$ was high. $V^{\prime} \mathrm{O}_{2}$ was not significantly different between $\mathrm{CV}$ and PTV (8.9 \pm 0.6 versus $9.5 \pm 0.8$, respectively) whereas it tended to increase to $10.8 \pm 1.1 \mathrm{~mL} \cdot \mathrm{min}^{-1} \cdot \mathrm{kg}^{-1}$ during SIMV and increased significantly to $11.9 \pm 0.8 \mathrm{~mL} \cdot \mathrm{min}^{-1} \cdot \mathrm{kg}^{-1}$. In the other nine infants whose OCB was normal, no significant variation of $V^{\prime} \mathrm{O}_{2}$ was observed.

Patient triggered ventilation was a weaning ventilatory mode that significantly reduced the increase in oxygen consumption observed in infants with a high oxygen cost of breathing, as compared to synchronous intermittent mandatory ventilation or continuous positive airway pressure. Further investigations in newborn infants with a high oxygen cost of breathing should be performed prior to routine use of patient triggered ventilation.

Eur Respir J 1997; 10: 2583-2585.

Weaning from artificial ventilation is a critical challenge, especially in newborn infants with chronic lung disease. We have previously shown that these newborn infants increase their oxygen consumption $\left(V^{\prime} \mathrm{O}_{2}\right)$ at the time of being weaned from mechanical ventilation [1]. This increase is secondary to a high oxygen cost of breathing (OCB) probably related to increased work of breathing, similar to that shown in adult patients [2]. Inspiratory pressure support, used during the weaning process in adult intensive care, may be useful in reducing the work of breathing [2]. Recent data have shown that patient triggered ventilation (PTV) decreases the work of breathing in premature neonates [3], and that PTV can be used as a weaning ventilatory mode [4-7]. We hypothesized that the increase in $V^{\prime} \mathrm{O}_{2}$ observed at the time of weaning in some newborn infants could be reduced by using PTV. We designed a study to assess $V^{\prime} \mathrm{O}_{2}$ during PTV as compared to synchronous intermittent mandatory ventilation (SIMV) and continuous positive airway pressure (CPAP) in newborn infants, before being weaned from mechanical ventilation.

\section{Methods}

The population was selected to include patients with normal and high OCB. Thus, in this prospective study, we included 16 infants requiring assisted ventilation for either acute respiratory distress (eight infants) or chronic lung disease (eight infants), after informed consent was obtained from the parents. The clinical characteristics, which covered a wide range, were at the time of measurement: gestational age; $33.9 \pm 1.0$ (range, $28 \pm 41$ ) weeks;
* Neonatal Dept, University Hospital of Nantes, Nantes, France. **Laboratory of Physiology, Hôpital Robert Debré, Paris, France.

Correspondence: J.C. Rozé

Service de Néonatalogie

Centre hospitalier

Universitaire

44035 Nantes

France

Keywords: Cost of breathing

mechanical ventilation

neonates

newborn infants

triggered ventilation

weaning

Received: March 211997

Accepted after revision July 231997 postnatal age; $18 \pm 4$ (2-65) days; postconceptional age; $36.5 \pm 1.3(31.3-48.3)$ weeks; and weight; $2.3 \pm 0.2(1.4-3.5)$ $\mathrm{kg}$.

$V^{\prime} \mathrm{O}_{2}$ and carbon dioxide production $\left(V^{\prime} \mathrm{CO}_{2}\right)$ were measured with a validated thermoregulated $\left(38 \pm 0.5^{\circ} \mathrm{C}\right)$ computerized device $[1,8]$. The equations used were those of the open circuit method, including inspiratory fraction of carbon dioxide $\left(\mathrm{FICO}_{2}\right)$. The expiratory minute volume of the ventilator was measured with a mass flowmeter (Job 630, Klogor, Lannion, France). Gas fractions were measured with a paramagnetic oxygen analyser (AO64, Klogor) and a carbon dioxide infra-red analyser (Gascard, Edinburgh Sencors Ltd., UK). Gas fractions were alternately analysed in inspired gas for $10 \mathrm{~s}$ and in expired gas for $80 \mathrm{~s}$. Between two epochs of measurements, a $30 \mathrm{~s}$ delay was required to flush all the plumbing. Unsedated babies were ventilated using a constant flow, time-cycled, pressure-limited ventilator with a flow trigger (Babylog 8000 with software 3, Dräger, Lübeck, Germany). Inspired and expired minute ventilation $\left(V^{\prime} \mathrm{E}\right)$ of the infant was measured with the hot wire anemometer of the ventilator. From this measurement, spontaneous ventilation was calculated by Babylog 8000 software as that part of expired $V^{\prime} E$ secondary to spontaneous breathing, and was expressed as a percentage of expired $V^{\prime}$ E. Furthermore, air leaks around the endotracheal tube were calculated as the difference between inspiratory and expiratory $V^{\prime} \mathrm{E}$ and was expressed as a percentage of inspiratory $V^{\prime} \mathrm{E} . V^{\prime} \mathrm{O}_{2}$ and $V^{\prime} \mathrm{CO}_{2}$ measurements were rejected if air leaks were detected, or if the difference between oxygen fractions of the inspiratory circuit measured at the beginning and 
end of the epoch was more than 0.0005 [8]. For each ventilation mode, measurements were started $10 \mathrm{~min}$ after change in ventilatory mode and performed during 21 epochs.

Three weaning ventilation modes were studied in random order in each newborn: PTV (peak inspiratory pressure $=10 \mathrm{cmH}_{2} \mathrm{O}$, inspiratory time $=0.3 \mathrm{~s}$, expiratory time $=4 \mathrm{~s}$ ), SIMV (peak inspiratory pressure $=10$ $\mathrm{cmH}_{2} \mathrm{O}$, inspiratory time $=0.3 \mathrm{~s}$, expiratory time $=4$ $\mathrm{s}$ ), and CPAP. The difference between PTV and SIMV was that most of the spontaneous effort is accompanied by respiratory support during PTV, but only 14 times per minute during SIMV. These three modes were compared with controlled ventilation (peak inspiratory pressure $=20 \mathrm{cmH}_{2} \mathrm{O}$, inspiratory time $=0.4 \mathrm{~s}$, expiratory time $=0.6 \mathrm{~s})$. Positive expiratory pressure during the four modes was $2 \mathrm{cmH}_{2} \mathrm{O}$.

OCB was defined as the $V^{\prime} \mathrm{O}_{2}$ difference between controlled ventilation (CV) and CPAP. OCB was expressed as a percentage of mean $V^{\prime} \mathrm{O}_{2}$ measured during CPAP. We considered OCB as normal when $<15 \%$. This value was chosen with regard to our previous report [1] in which OCB was $4.8 \pm 4.9 \%$ in a population of neonates who had been weaned without difficulty. The 16 infants were divided into normal or high OCB groups according to whether OCB was less or more than $15 \%$. Once $V^{\prime} \mathrm{O}_{2}$ measurements were performed, infants were weaned from mechanical ventilation using CPAP during $1 \mathrm{~h}$ and then extubated. Duration of oxygen therapy after weaning was assessed for each infant.

The number of patients needed to show a $V^{\prime} \mathrm{O}_{2}$ difference between CPAP and PTV more than $2 \mathrm{~mL} \cdot \mathrm{min}^{-1} \cdot \mathrm{kg}^{-1}$ in infants with high OCB, as well as to set the probability of a type 1 error at 0.05 and a type 2 error at 0.20 , was determinated on the basis of data from our previous report [1]. It was calculated to be seven in the high OCB group (each patient being his or her own control). Results are expressed as mean \pm SEM. Analysis of variance (ANOVA) and ANOVA for repeated measurements were used to compare results between the two groups and within each group, respectively. Linear regression was performed to study the relationship between $V^{\prime} \mathrm{O}_{2}$ and spontaneous ventilation. Institutional approval was obtained for this study.

\section{Results}

OCB was high in seven infants $(23.0 \pm 4.7 \%)$ and normal in the other nine infants $(-2.3 \pm 4.7 \%)$. The clinical characteristics of the high and normal OCB groups at the time of measurements are indicated on table 1 . The duration of oxygen therapy after weaning was greater in the high OCB group than in the normal OCB group $(114 \pm 44$ and $25 \pm 10$ days, respectively $(\mathrm{p}=0.05)$ ).

Figure 1 and table 2 show $V^{\prime} \mathrm{O}_{2}$ variations according to ventilatory modes for each group. In the high OCB group, $V^{\prime} \mathrm{O}_{2}$ was not significantly different between $\mathrm{CV}$ $(8.9 \pm 0.6)$ and PTV $(9.5 \pm 0.8)$ whereas it tended to increase to $10.8 \pm 1.1 \mathrm{~mL} \cdot \mathrm{min}^{-1} \cdot \mathrm{kg}^{-1}$ during SIMV and increased significantly to $11.9 \pm 0.8 \mathrm{~mL} \cdot \mathrm{min}^{-1} \cdot \mathrm{kg}^{-1}$ during CPAP $(\mathrm{p}<0.012)$. In the normal OCB group $V^{\prime} \mathrm{O}_{2}$ did not vary significantly. The $V^{\prime} \mathrm{O}_{2}$ increase was correlated with the increase in spontaneous ventilation $\left(\mathrm{r}^{2}=0.19, \mathrm{~F}_{[1,26]}=\right.$ $5.94 ; \mathrm{p}<0.03)$. The percentage of spontaneous ventila-
Table 1. - Clinical characteristics at time of study

\begin{tabular}{lrrc}
\hline Groups & $\begin{array}{c}\text { Normal OCB } \\
\mathrm{n}=9\end{array}$ & $\begin{array}{c}\text { High OCB } \\
\mathrm{n}=7\end{array}$ & $\mathrm{p}$ \\
\hline Gestational age weeks & $33.2 \pm 1.4$ & $34.2 \pm 1.6$ & $\mathrm{NS}$ \\
Postnatal age days & $9.4 \pm 2.5$ & $29.9 \pm 7.6$ & 0.05 \\
Postconceptional age & $34.6 \pm 1.4$ & $39.0 \pm 2.1$ & 0.05 \\
$\quad$ weeks & $2.3 \pm 0.3$ & $2.3 \pm 0.3$ & $\mathrm{NS}$ \\
Weight kg &
\end{tabular}

Data are presented as mean \pm SEM; OCB: oxygen cost of breathing; NS: nonsignificant.

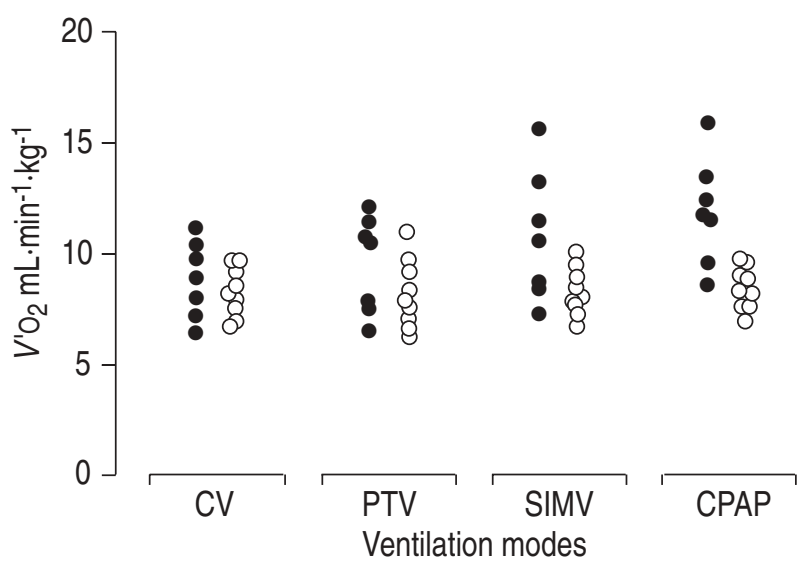

Fig. 1. - Mean individual oxygen consumption at the time of weaning in 16 infants. $\bullet$ : nine infants with normal oxygen cost of breathing (OCB); $O$ : seven infants with high OCB. The measurements were performed during controlled ventilation $(\mathrm{CV})$ and three ventilatory modes used to wean neonates from mechanical ventilation. PTV: patient triggered ventilation; SIMV: synchronized intermittent mandatory ventilation; CPAP: continuous positive airway pressure.

tion increased from $2 \%$ during PTV to $75 \%$ during SIMV and $100 \%$ during CPAP $(\mathrm{p}<0.001)$. In the normal OCB group, no significant variations in $V^{\prime} \mathrm{O}_{2}$ were observed in the different ventilatory modes.

\section{Discussion}

The main finding in our study was that the PTV mode can significantly reduce the increase in $V^{\prime} \mathrm{O}_{2}$ observed in some infants at the time of weaning [1], as compared to SIMV or CPAP. PTV significantly reduced $V^{\prime} \mathrm{O}_{2}$ by $20 \%$ in newborn infants with high OCB, as compared to CPAP. This decrease in $V^{\prime} \mathrm{O}_{2}$ during PTV was higher than the absolute intra-infant biological variation of $V^{\prime} \mathrm{O}_{2}$ [9]. This decrease was probably related in part to a decrease in the work of breathing as observed in adults [2] or children [10] during pressure support ventilation. Furthermore, PTV has been shown to reduce the work of breathing in premature infants [3].

In association with reduction in $V^{\prime} \mathrm{O}_{2}$ increase, PTV reduced the percentage of spontaneous ventilation. The beneficial effect of PTV resulted from the assistance of each respiratory breath and from the adequate synchronization of mechanical breath with spontaneous ventilation [3]. This point is of major impact in premature infants who spend most of their sleep time in active sleep. Active sleep is characterized by less dependence on mechanical ventilation than quiet sleep [11].

We did not observe a significant reduction in $V^{\prime} \mathrm{O}_{2}$ increase during SIMV at low frequency, as compared to CPAP. This lack of efficacy is probably more related to the large proportion of spontaneous ventilation 
Table 2. - Mean oxygen consumption $\left(\mathrm{V}^{\prime} \mathrm{O}_{2}\right)$, mean carbon dioxide production $\left(\mathrm{V}^{\prime} \mathrm{CO}_{2}\right)$, respiratory quotient, minute ventilation $\left(V^{\prime} E\right)$ and percentage of spontaneous ventilation (SV) according to ventilation modes in infants with high and normal oxygen cost of breathing (OCB), at time of weaning.

\begin{tabular}{|c|c|c|c|c|c|c|}
\hline & & $\begin{array}{l}\text { Controlled } \\
\text { ventilation }\end{array}$ & $\begin{array}{l}\text { Patient-triggered } \\
\text { ventilation }\end{array}$ & $\begin{array}{c}\text { Synchronized } \\
\text { intermittent mandatory } \\
\text { ventilation }\end{array}$ & $\begin{array}{c}\text { Continuous } \\
\text { positive airway } \\
\text { pressure }\end{array}$ & $\mathrm{p}^{+}$ \\
\hline \multirow{2}{*}{$V^{\prime} \mathrm{O}_{2} \quad \mathrm{~mL} \cdot \mathrm{min}^{-1} \cdot \mathrm{kg}^{-1}$} & High & $8.9 \pm 0.6$ & $9.5 \pm 0.8$ & $10.8 \pm 1.1 *$ & $11.9 \pm 0.9 * * *$ & 0.012 \\
\hline & Low & $8.3 \pm 0.4$ & $8.2 \pm 0.5$ & $8.2 \pm 0.4 *$ & $8.3 \pm 0.3 * * *$ & NS \\
\hline \multirow{2}{*}{$V^{\prime} \mathrm{CO}_{2} \quad \mathrm{~mL} \cdot \mathrm{min}^{-1} \cdot \mathrm{kg}^{-1}$} & High & $8.0 \pm 0.7$ & $8.2 \pm 0.6$ & $8.6 \pm 0.6^{*}$ & $10.8 \pm 0.7 * * *$ & 0.014 \\
\hline & Low & $7.5 \pm 0.4$ & $7.3 \pm 0.5$ & $7.1 \pm 0.3 *$ & $7.4 \pm 0.3 * * *$ & NS \\
\hline \multirow{2}{*}{ Respiratory quotient } & High & 0.9 & 0.9 & 0.8 & 0.9 & 0.022 \\
\hline & Low & 0.9 & 0.9 & 0.9 & 0.9 & NS \\
\hline \multirow[t]{2}{*}{$V^{\prime} \mathrm{E} \quad \mathrm{mL} \cdot \mathrm{min}^{-1} \cdot \mathrm{kg}^{-1}$} & High & $312 \pm 18$ & $277 \pm 27$ & $265 \pm 25$ & $318 \pm 23$ & 0.052 \\
\hline & Low & $316 \pm 29$ & $313 \pm 37$ & $304 \pm 42$ & $307 \pm 37$ & NS \\
\hline \multirow[t]{2}{*}{ SV \% } & High & $10 \pm 3$ & $2 \pm 1$ & $76 \pm 2$ & 100 & 0.001 \\
\hline & Low & $10 \pm 4$ & $2 \pm 1$ & $69 \pm 7$ & 100 & 0.001 \\
\hline
\end{tabular}

Results are expressed as mean \pm SEM; Ns: nonsignificant; ${ }^{+}$: analysis of variance for repeated measurements within each group; *: $\mathrm{p}=0.031$ between two groups during synchronized intermittent mandatory ventilation; $* * *: \mathrm{p}<0.001$ between two groups during continuous positive airway pressure. High: seven patients with high oxygen cost of breathing (OCB); Normal: nine patients with normal $\mathrm{OCB} ; V^{\prime} \mathrm{O}_{2}$ : oxygen consumption; $V^{\prime} \mathrm{CO}_{2}$ : carbon dioxide production.

without mechanical assistance during SIMV with the unopposed presence of the endotracheal tube, than to the asynchrony between spontaneous and mechanical ventilation, since the rate of asynchrony was probably low $(<5 \%)$ in this condition (low frequency and an inspiratory time of less than $0.4 \mathrm{~s}$ ) [12].

Among the different ventilatory modes which can be used to wean neonates, PTV is a mode maintaining an inspiratory effort from the patient [13] and thus an exercise of respiratory muscles without excessive increase of $V^{\prime} \mathrm{O}_{2}$ as well as work of breathing. Thus, PTV seems to be an interesting ventilatory mode to wean infants with high OCB, as proposed in adults [2, 14]. However, no clinical trial to date has confirmed this in neonates. Only three trials published in two reports $[6,7]$ have compared PTV and SIMV during weaning periods. No major differences were observed between the two modes in terms of failure or duration of weaning, except in one trial in which duration of weaning was significantly shorter with PTV [7]. However, in theses studies, no $V^{\prime} \mathrm{O}_{2}$ or work of breathing measurements were performed. These studies, thus, failed to show any major difference between PTV and SIMV because some of the infants probably did not have a high OCB and were, therefore, easily weaned off mechanical ventilation [15]. In fact, in our study, the group of patients with normal OCB showed no significant variations in $V^{\prime} \mathrm{O}_{2}$ during the different ventilation modes, and most were easily weaned.

In conclusion, patient triggered ventilation is a weaning ventilatory mode which can significantly reduce the increase in oxygen consumption observed during continuous positive airway pressure in infants with a high oxygen cost of breathing. Further investigations in newborn infants with a high oxygen cost of breathing should be performed prior to routine use of patient triggered ventilation.

\section{References}

1. Rozé JC, Chambille B, Fleury MA, Debillon Th, Gaultier Cl. Oxygen cost of breathing in newborn infants with long-term ventilatory support. $J$ Pediatr 1995; 127: 984-987.
2 Brochard L, Harf A, Lorino H, Lemaire F. Inspiratory pressure support prevents diaphragmatic fatigue during weaning from mechanical ventilation. Am Rev Respir Dis 1989; 139: 513-521.

3. Jarreau PH, Moriette G, Mussat P, et al. Patient-triggered ventilation decreases the work of breathing in neonates. Am J Respir Crit Care Med 1996; 153: 1176-1181.

4. Donn SM, Nicks JJ, Becker MA. Flow synchronised ventilation of preterm infants with respiratory distress syndrome. J Perinatol 1994; 14: 90-94.

5. Chan V, Greenough A. Randomised controlled trial of weaning by patient triggered ventilation or conventional ventilation. Eur J Pediatr 1993; 152: 925-927.

6. Chan V, Greenough A. Comparison of weaning by patient triggered ventilation or synchronous intermittent mandatory ventilation in preterm infants. Acta Paediatr 1994; 83: 335-337.

7. Dimitriou G, Greenough A, Giffin F, Chan V. Synchronous intermittent mandatory ventilation modes compared with patient triggered ventilation during weaning. Arch Dis Child 1995; 72: F188-190.

8. Rozé JC, Chambille B, Dehan M, Gaultier Cl. Measurement of oxygen uptake in newborn infants during assisted and spontaneous ventilation. Respir Physiol 1994; 98: 227-239.

9. Marks KH, Nardis EE, Derr JA. Day-to-day energy expenditure variability in low birth weight neonates. Pediatr Res 1987; 21: 66-71.

10. EI-Khatib MF, Chatburn RL, Potts DL, Blumer JL, Smith PG. Mechanical ventilators optimized for pediatric use decrease work of breathing and oxygen consumption during pressure-support ventilation. Crit Care Med 1994; 22: 1942-1948.

11. Curzy-Dascalova L, Relier JP, Peirano P, Castex M, Vasseur O. Degree of dependence on the ventilator according to sleep states in artificially ventilated premature infants. Am J Perinatal 1986; 3: 169-173.

12. Bernstein G, Cleary JP, Heldt GP, Rosas F, Schellenberg LD, Mannino FL. Response time and reliability of three neonatal patient-triggered ventilators. Am Rev Respir Dis 1993; 148: 358-364.

13. Lorino H, Moriette G, Mariette C, Lorino AM, Harf A., Jarreau PH. Inspiratory work of breathing in ventilated preterm infants. Pediatr Pulmonol 1996; 21: 323-327.

14. Mancebo J. Weaning from mechanical ventilation. Eur Respir J 1996; 9: 1923-1931.

15. Brandstetter RD, Tamarin F. Weaning is demeaning. It's time for liberation! Chest 1992; 101: 1488. 